\title{
Murine Models of Acute Alcoholic Hepatitis and Their Relevance to Human Disease
}

\author{
Richard J.W. Wilkin, ${ }^{{ }^{\dagger}}$ Patricia F. Lalor,${ }^{{ }^{\dagger}}$ Richard Parker, ${ }^{{ }^{\dagger}}$ and Philip N. Newsome ${ }^{*^{\dagger}}$
}

From the National Institute for Health Research Birmingham Liver Biomedical Research Unit and Centre for Liver Research,* University of Birmingham, Birmingham; and the Liver Unit, ${ }^{\dagger}$ University Hospital Birmingham NHS Foundation Trust, Birmingham, United Kingdom

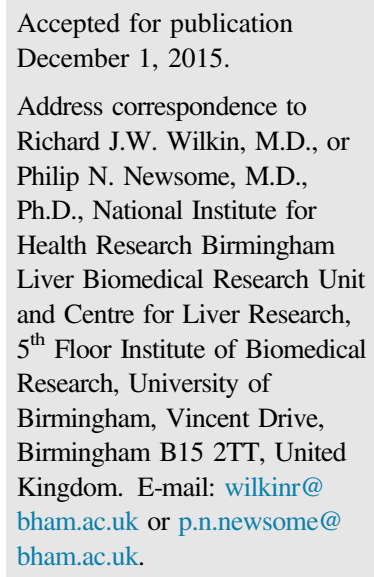

\begin{abstract}
Alcohol-induced liver damage is a major burden for most societies, and murine studies can provide a means to better understand its pathogenesis and test new therapies. However, there are many models reported with widely differing phenotypes, not all of which fully regenerate the spectrum of human disease. Thus, it is important to understand the implications of these variations to efficiently model human disease. This review critically appraises key articles in the field, detailing the spectrum of liver damage seen in different models, and how they relate to the phenotype of disease seen in patients. A range of different methods of alcohol administration have been studied, ranging from ad libitum consumption of alcohol and water to modified diets (eg, Lieber deCarli liquid diet). Other feeding regimens have taken more invasive routes using intragastric feeding tubes to infuse alcohol directly into the stomach. Notably, models using wild-type mice generally produce a milder phenotype of liver damage than those using genetically modified mice, with the exception of the chronic binge-feeding model. We recommend panels of tests for consideration to standardize end points for the evaluation of the severity of liver damage-key for comparison of models of injury, testing of new therapies, and subsequent translation of findings into clinical practice. (Am J Pathol 2016, 186: 748-760; http:// dx.doi.org/10.1016/j.ajpath.2015.12.003)
\end{abstract}

The burden of alcohol and related liver disease is significant, in terms of both human and financial costs. In 2010, 7.2 deaths per 100,000 individuals globally were caused by alcohol-related cirrhosis, equating to $0.9 \%$ of deaths from all causes. ${ }^{1}$ The economic burden is much more difficult to calculate, and the World Health Organization estimated that in 2003, the total tangible cost of alcohol to European Union society was 125 billion euros, with nontangible costs (value placed on pain, suffering, and lost life because of social and health harms caused by alcohol) amounting to 150 to 760 billion euros. $^{2}$ Although alcohol excess is a major cause of cirrhosis, as many as $60 \%$ of patients presenting with alcohol-induced liver damage also have evidence of concomitant acute alcoholic hepatitis (AAH). ${ }^{3}$ As the most dramatic presentation of alcohol-induced liver injury, AAH has a much higher short- and long-term mortality, approaching $20 \%$ and $50 \%$, respectively, despite current medical therapy. ${ }^{4,5}$ The understanding of its pathogenesis, and hence development of novel therapies, has been, in part, hampered by the lack of relevant, reproducible, animal models of AAH.

Although there are limitations of using animal models to investigate alcoholic liver injury, this approach does provide research opportunities not found in in vitro or clinical studies. Animal models allow control over multiple pathogenetic factors, such as the environment, the contribution of specific pathways, and the amount of alcohol consumed, which are difficult to replicate in human studies. Mice that are transgenic for key inflammatory and metabolic

\footnotetext{
Supported by UHB Charities (R.J.W.W.), the National Institute for Health Research Biomedical Research Unit (P.N.N. and P.F.L.), and an EASL Sheila Sherlock Physician Scientist Fellowship (R.P.). This paper presents independent research supported by the Birmingham NIHR Liver Biomedical Research Unit based at the University Hospital Birmingham NHS Foundation Trust and the University of Birmingham.

The views expressed are those of the author(s) and not necessarily those of the NHS, the NIHR or the Department of Health.

Disclosures: None declared.
} 
disease-modifying genes are widely available, and confer the ability to assess the impact of regulatory processes on the induction of alcoholic liver injury ${ }^{7}$ (Table 1). Although transgenic rats are available, their use has been restricted by a limited knowledge of their reproductive system and more difficult in vitro embryo manipulation, which is needed to develop transgenic breeds. Therefore, in this review, we will critically appraise the published models of acute murine alcohol-induced liver injury, paying particular attention to the parameters used to define the extent of liver damage, to highlight advantages of those models with the greatest promise for new treatment options.

\section{Phenotype of Disease}

Alcohol induces a broad spectrum of liver injury in patients, ranging from steatosis to more florid inflammation and hepatocyte necrosis, and finally to fibrosis and the development of hepatocellular carcinoma. The particular phenotype induced is determined, in part, by the quantity and duration of alcohol exposure and patient-specific factors. A variety of models have been used by researchers to model this spectrum, ${ }^{6}$ with each using a different method of alcohol administration to produce a wanted pattern of liver injury. In general, however, although many of the available murine models reproduce some of the early stages of liver injury, the development of fibrosis and cirrhosis is harder to replicate and commonly requires an injury additional to alcohol exposure. Thus, although steatosis has been achieved by ad libitum feeding for between approximately 1 week to several months, ${ }^{7,21}$ most models require a second insult alongside an extended course of alcohol administration to induce fibrosis, such as either concomitant genetic manipulation ${ }^{14}$ (Table 2) or the addition of a second chemical insult, such as carbon tetrachloride. ${ }^{37}$

\section{Use of Wild-Type Mice to Model Alcohol-Induced Liver Damage}

Alcohol has been administered to mice by a variety of different routes/regimens, each having their respective advantages and disadvantages (Table 2). The choice of model is often governed by the features of liver injury that are required and the skills/resources available. The simplest method of administering alcohol, known as ad libitum, is to mix it into the drinking water and allow the mice free access to this alongside their normal chow. However, because of a natural aversion to alcohol, the mice generally only develop low blood alcohol levels (BALs) and mild liver injury. ${ }^{23}$ This model can be useful in some circumstances because it replicates human patterns of alcohol exposure and dietary intake. The other ad libitum option involves the addition of alcohol to a Lieber deCarli (LdC) diet, in which normal mouse chow is replaced by a high-fat, nutritionally complete liquid diet. This partially overcomes the murine dislike of alcohol and tends to produce a more significant liver injury than the conventional water/alcohol mix. ${ }^{27}$ There is conflicting evidence as to whether the increased liver injury is a reflection of higher BALs or the additive effect of combining a high-fat diet with alcohol exposure. ${ }^{38}$

Another ad libitum method is to provide the ethanol in an agar gel. ${ }^{39}$ This has been used much less commonly than a liquid diet, although there is some evidence that the alcohol evaporation from a gel is low. The model was developed to try and simplify the administration of alcohol. The gel diet does appear to induce a liver injury - the alcohol-fed mice developed a significantly higher steatosis score, triglyceride level, and alanine aminotransferase (ALT) level than control mice not fed alcohol. The drawback for this method is the complicated gel preparation and custom-made feeding tubes required. In contrast, the $\mathrm{LdC}$ liquid diet is easier to make, and Richter tubes are a simple delivery method.

Another approach consists of administering alcohol via gavage directly into the animal's stomach, which is a relatively straightforward procedure that can be easily taught. ${ }^{40}$ However, the procedure needs to be repeated on a daily basis, thus inducing stress in the mouse, and again only produces mild liver injury with a $25 \%$ increase in serum ALT levels in ethanol-fed animals. ${ }^{30}$ The gavage model can be used in combination with ad libitum delivery of alcohol, such as in the chronic binge model, ${ }^{40}$ where mice have access to a LdC/ethanol mix and also receive a single gavage of ethanol on the day the experiment is terminated. This produces a more significant liver injury than just gavage or ad libitum delivery alone, with peak levels of ALT and aspartate aminotransferase (AST) 9 hours after gavage of 250 and $420 \mathrm{IU}$, respectively. ${ }^{31}$ Notably, there is also evidence of greater triglyceride deposition in the liver and increased hepatic inflammation in the chronic binge group. The ability of this relatively simple model to induce a moderately severe alcoholic liver injury has led to its adoption by many groups. ${ }^{32}$

Recently, a hybrid model of a solid chow high in cholesterol and saturated fat, along with intragastric feeding of a liquid high-fat/ethanol diet, has been developed by Lazaro et al. ${ }^{41}$ The intragastric feeding model was first described by Tsukamoto et al. $^{34}$ and involves complex surgery to place a tube through the skin into the rodent's stomach. This tube is then used to administer feed and alcohol to the mouse. It has been shown to produce higher BALs (between 100 and $500 \mathrm{mg} / \mathrm{dL}$ in rats) ${ }^{6}$ and a more severe liver injury than ad libitum feeding methods. ${ }^{33}$ The hybrid model produces a liver injury consistent with chronic alcoholic steatohepatitis-with a marked transaminase increase, and significant steatosis with inflammation and occasional neutrophil infiltration present. The addition of weekly alcohol binges induces an increased neutrophil infiltration with clustering seen around dead and fat-loaded hepatocytes. This provides a better representation of an AAH injury (Figure 1). 
Table 1 Summary of Current Transgenic Models of Alcohol-Induced Liver Injury

\begin{tabular}{lll}
\hline Genetic manipulation & Function of key gene & Liver injury indexes \\
\hline $\begin{array}{ll}\text { Hepatic } A D H \text { knockout, ad libitum } \\
\mathrm{LdC}+1 \%, 2 \% \text {, or } 3.5 \%\end{array}$ & $\begin{array}{c}\text { ADH catalyzes the oxidation of } \\
\text { ethanol, the main pathway by }\end{array}$ & $\begin{array}{c}\text { No significant oxidative stress } \\
\text { levels or inflammatory }\end{array}$ \\
$\mathrm{EtOH}^{8,9}$ & $\begin{array}{l}\text { which ethanol is metabolized } \\
\text { during chronic alcohol abuse. }\end{array}$ & $\begin{array}{l}\text { response. Produced pan lobar } \\
\text { vacuolization in response to }\end{array}$ \\
& & $3.5 \%$ EtOH diet.
\end{tabular}

Conclusions

Dose of ethanol and ADH deficiency are key factors in initiation and progression of alcoholic fatty liver disease. The ADH KO mice produced higher BALs ${ }^{9}$ and consequently increased hepatic lipid vacuolization. Deer mice and this model can be used to study chronic alcoholic liver injury.

BiP (heavy chain immunoglobulin binding protein/Grp78) knockout, ad libitum high-fat diet $+4 \mathrm{~g}$ alcohol $/ \mathrm{kg}$ body weight $^{10}$

CHOP knockout, intragastric infusion of high-fat diet +18 $\mathrm{g} / \mathrm{kg}$ per day increased to 29 $\mathrm{g} / \mathrm{kg}$ per day of alcohol for a total of 4 weeks $^{11}$

Cyp2e1 knockout, intragastric infusion of high-fat diet +14 $\mathrm{g} / \mathrm{kg}$ per day increased to 28 $\mathrm{g} / \mathrm{kg}$ per day of alcohol for a total of 4 weeks ${ }^{12}$

Gsta4-4/Ppara double knockout, ad libitum $5 \%$ ethanol/LdC for 40 days $^{13}$

Hfe knockout, high-fat diet, and ad libitum water + alcohol at $20 \% \mathrm{v} / \mathrm{v}$ for 8 weeks $^{14}$

Hif1a knockout mice, ad libitum $6 \%$ ethanol/LdC diet for 4 weeks $^{15}$

Lipin1 knockout, ad libitum lowfat LdC + alcohol for 4 weeks $^{16 *}$

Nrf2 knockout, ad libitum $\mathrm{LdC}+$ $2.1 \% \mathrm{v} / \mathrm{v}$ alcohol for $3 / 7,4.2 \%$ for $3 / 7$, followed by $6.3 \%$ alcohol until the mice became moribund $^{7}$
BiP mediates the unfolded protein response that reduces protein translation, enhances protein folding, and increases degradation of unfolded proteins. This serves as a model of ER stress with alcohol added to study the development of HCC.

CHOP is a transcriptional regulator involved in apoptosis caused by ER stress.

Cyp2e1 (cytochrome P450) is induced in the hepatocyte by ethanol and appears to correlate with the level of liver injury.

Gsta4-4 is a detoxification enzyme that eliminates toxins via glutathione conjugation. Ppar- $\alpha$ is a hormone receptor that regulates hepatic inflammation and lipid metabolism.

Model of iron overload consistent with hemochromatosis.

HIF is a master controller adapting to hypoxia by controlling expression of hundreds of genes.

Lipin-1 is a vital regulator of lipid metabolism.

Nrf2 is a transcription factor that protects against oxidative stress.
Increased ALT to approximately $320 \mathrm{U} / \mathrm{L}$ in BiP $\mathrm{KO}$ mice compared with approximately $45 \mathrm{U} / \mathrm{L}$ in WT mice. Also showed increased lipid accumulation and increased rate of $\mathrm{HCC}$.

WT and transgenic mice had significant changes in steatosis score, liver triglyceride levels (fivefold increase in WT but $50 \%$ decrease in $\mathrm{CHOP}^{-/-}$mice), and ALT (112 U/L). CHOP ${ }^{-/-}$ mice had no apoptosis.

Mild steatosis, slight inflammation, and necrosis, as shown by pathology scores.

Produces increased hepatic injury with significantly increased inflammatory response, necrosis, and fibrosis.

Produces profound steatohepatitis, significant fibrosis, and increased apoptosis.

Increased steatosis, serum, and liver cholesterol and triglycerides.

Produces an ALT of $90 \mathrm{U} / \mathrm{L}$ with fibrosis in Lpin1 knockout mice after 4 weeks of feeding.

An ALT of $3000 \mathrm{U} / \mathrm{L}$ and severe steatosis with increased number of Kupffer cells.
$\mathrm{HCCs}$ were only found in the KO mice, suggesting that more than one insult needs to be present to induce carcinogenesis. Alcoholinduced stress was age related, with younger animals more resistant to stress.

As a response to ER stress, $C H O P$ up-regulates and causes apoptosis.

Shows that CYP2E1 has a minimal role in early alcohol-induced liver injury.

Shows the importance of lipid peroxidation products mediating the early progression of ALD.

Highlights a combined effect of iron overload, alcohol, and a high-fat diet cause significant steatosis, inflammation, oxidative stress, and apoptosis. HIF1a induction provides protection against alcoholinduced fatty liver disease and modulating its activity may provide therapeutic potential.

Suggests a role for treatments to enhance lipin-1 as a treatment for ALD.

Central role for Nrf2 in the protection against alcoholinduced liver injury. 
Table 1 (continued)

\begin{tabular}{|c|c|c|c|}
\hline Genetic manipulation & Function of key gene & Liver injury indexes & Conclusions \\
\hline $\begin{array}{l}\text { Ppara knockout, gavage of } 0.4 \\
\mathrm{~mL} / 10 \mathrm{~g} 52 \% \text { erguotou wine } \\
\text { for } 4 / 52^{17}\end{array}$ & $\begin{array}{l}\text { Ppar } \alpha \text { stimulates fatty acid } \\
\text { catabolism under fasting } \\
\text { conditions (similar to chronic } \\
\text { alcohol ingestion). }\end{array}$ & $\begin{array}{l}\text { Fibrosis in knockout mice fed } \\
\text { ethanol for } 4 \text { to } 6 \text { months, } \\
\text { with severe steatosis and } \\
\text { inflammatory cell infiltration. }\end{array}$ & $\begin{array}{l}\text { Suggests a pathway for alcohol } \\
\text { metabolism. Possible role for } \\
\text { Ppar } \alpha \text { agonists in treatment } \\
\text { of ALD. }\end{array}$ \\
\hline $\begin{array}{l}\text { Srebp-1c knockout, intragastric } \\
\text { infusion of high-fat diet }+ \\
18 \mathrm{~g} / \mathrm{kg} \text { per day of alcohol } \\
\text { increased to } 29 \mathrm{~g} / \mathrm{kg} \text { per day } \\
\text { for a total of } 4 \text { weeks }{ }^{18}\end{array}$ & $\begin{array}{l}\text { SREBPs are normally induced in } \\
\text { the liver by alcohol. They have } \\
\text { an essential role in hepatic } \\
\text { triglyceride and cholesterol } \\
\text { synthesis. }\end{array}$ & $\begin{array}{l}\text { ALT increases up to } 118 \text { in WT } \\
\text { mice and } 80 \text { in Srebp-1c } \\
\text { mice with a steatosis score of } \\
3.2 \text { in WT and } 0.9 \text { in K0 mice. }\end{array}$ & $\begin{array}{l}\text { Shows that hepatic triglyceride } \\
\text { accumulation is dependent on } \\
\text { Srebp-1c. }\end{array}$ \\
\hline $\begin{array}{l}\text { Stat3 knockout, ad libitum } \mathrm{LdC}+ \\
5 \% \text { alcohol for } 10 / 7 \text {, followed } \\
\text { by a gavage of } 5 \mathrm{~g} / \mathrm{kg} \text { of } \\
\text { alcohol }{ }^{19}\end{array}$ & $\begin{array}{l}\text { Involved in the activation of } \\
\text { IL-22-a cytokine involved in } \\
\text { controlling bacterial infection, } \\
\text { homeostasis, and tissue repair. }\end{array}$ & $\begin{array}{l}\text { Produces significantly higher ALT } \\
(300 \mathrm{U} / \mathrm{L}), \text { AST }(450 \mathrm{U} / \mathrm{L})+ \\
\text { triglycerides }(50 \mathrm{mg} / \mathrm{g}) \text {, with } \\
\text { microsteatosis. }\end{array}$ & $\begin{array}{l}\text { Shows the hepatoprotective role } \\
\text { of IL-22 is dependent on } \\
\text { Stat3. }\end{array}$ \\
\hline $\begin{array}{l}\text { TNFR1 knockout, intragastric } \\
\text { infusion of high-fat diet }+ \\
18 \mathrm{~g} / \mathrm{kg} \text { per day of alcohol } \\
\text { increased to } 29 \mathrm{~g} / \mathrm{kg} \text { per day } \\
\text { for a total of } 4 \text { weeks }\end{array}$ & $\begin{array}{l}\text { TNF- } \alpha \text { is released by Kuppfer } \\
\text { cells primed by gut endotoxins } \\
\text { and plays a major role in early } \\
\text { alcoholic liver injury; its effect } \\
\text { is stopped if its receptor } \\
\text { (TNFR1) is knocked out. }\end{array}$ & $\begin{array}{l}\text { K0 mice have smaller increases } \\
\text { in ALT ( } 45 \text { vs } 115 \mathrm{U} / \mathrm{L}) \text {, liver } \\
\text { triglycerides ( } 0.27 \mathrm{vs} 0.34 \mathrm{mg} / \\
\text { mg), inflammatory foci, and } \\
\text { apoptotic cells than WT mice. }\end{array}$ & $\begin{array}{l}\text { ALD has multiple complex } \\
\text { pathways; TNF- } \alpha \text { has a modest } \\
\text { contribution to the liver injury } \\
\text { seen. }\end{array}$ \\
\hline
\end{tabular}

*Ethanol level calculated according to percentage of calories in the liquid diet. Mice given $29 \%$ of the daily calories as ethanol.

ADH, antidiuretic hormone; ALD, alcoholic liver disease; ALT, alanine aminotransferase; AST, aspartate aminotransferase; BAL, blood alcohol level; CHOP, C/EBP-homologous protein of $29 \mathrm{kDa}$; ER, endoplasmic reticulum; Gsta4-4, glutathione S-transferase A4-4; HCC, hepatocellular carcinoma; HIF, hypoxiainducible factor; K0, knockout; LdC, Lieber deCarli; Nrf2, nuclear factor-erythroid 2-related factor 2; Ppar, peroxisome proliferator activated receptor; SREBP, sterol response element binding protein; TNF- $\alpha$, tumor necrosis factor- $\alpha$; WT, wild type.

The length of high-fat diet administration has been investigated by Chang et al, ${ }^{42}$ who fed mice for either 3 days or 3 months of high-fat diet with a single gavage of alcohol on the final day of feeding. This model increased ALT/AST in both models, with higher levels in the 3 -month model. Increases in infiltrated neutrophils and serum free fatty acids were also seen; however, the activation markers of macrophages were only slightly increased by the alcohol binge compared with the model without the alcohol. This seems to partially correlate with the human picture of alcoholic hepatitis.

The diet composition is also important. Charles Lieber and Leonore deCarli developed their eponymously named diet to accentuate the liver injury that could be induced by alcohol administration, and it has since been shown that a diet that is high in saturated fats can reduce hepatic lipid accumulation, whereas a diet containing polyunsaturated fats promotes liver injury. You et $\mathrm{al}^{43}$ found that adiponectin mediated the protective effect of saturated fats, which may provide therapeutic options that should be explored. However, recently, Chen et $\mathrm{al}^{44}$ showed that, although saturated fats can reduce hepatic fat deposition, they increased fibrotic changes within the liver. More importantly, most murine studies follow a pair-fed diet protocol. This involves matching the amount of diet without alcohol that is provided to control mice to the amount of diet and alcohol that the main study mice consumed in the previous 24 hours. This provides a control group to show that the liver injury is because of the alcohol and not the high-fat diet. Ultimately, logistical issues may determine choice of regimen. ad libitum models require considerably less expertise and specialist equipment, whereas the more involved intragastric feeding model requires metabolic cages, single mouse housing, specialist infusion equipment, and surgery to be performed by the researcher.

In wild-type (WT) mice, the severity of liver damage is closely linked to the duration and quantity of alcohol consumption, both of which are strongly influenced by the method of alcohol delivery. The ad libitum methods are limited by the mouse's appetite, whereas the intragastric feeding method is limited by the length of time the mouse can tolerate a feeding cannula in its stomach. Consequently, the duration of each model is determined by both the tolerability of the model and the level of liver injury that is required. Thus, although there are advantages to using WT mice in such studies, the extended duration of alcohol exposure needed to generate more severe liver injury may be challenging, highlighting the potential advantages of using transgenic mice that have an increased susceptibility to the injurious effects of alcohol.

\section{Models of Alcohol-Induced Liver Damage Using Genetically Modified Mice}

To date, multiple different regulatory and metabolic genes have been knocked out to assess their impact on the process of liver injury (Table 1). Some of these affect normal pathways of ethanol metabolism or metabolism of harmful 
Table 2 Established Routes for Administration of Alcohol to Mice

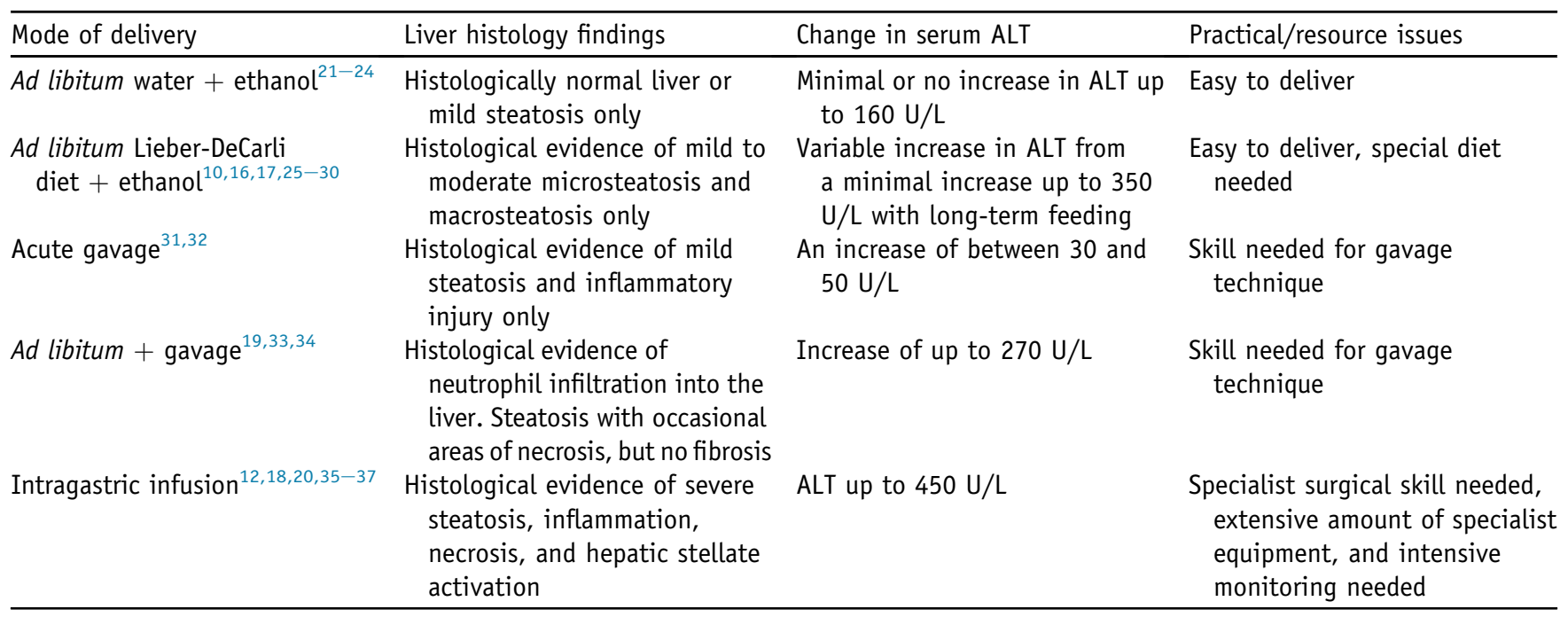

ALT, alanine aminotransferase.

by-products of ethanol, such as the Nrf2 knockout mouse that is susceptible to oxidative stress caused by alcohol breakdown products. $^{7}$ Others, such as the $\mathrm{Hfe}$ knockout mouse, which results in hepatic iron overload, augment the injurious effect of alcohol. ${ }^{22}$ Some of the more commonly used models with profound phenotypes are described in greater detail below, with a more comprehensive summary of models in Table 1.

Nuclear factor-erythroid 2-related factor 2 (Nrf2) protects cells against xenobiotic and oxidative stress, such that mice with this gene knocked out incur a severe, acute form of acute liver injury after alcohol ingestion. ${ }^{7}$ Mice are typically given 3 days of the $\mathrm{LdC}$ diet for accustomization purposes, and then alcohol is added at increasing concentrations of $2.1 \%, 4.2 \%$, and $6.4 \% \mathrm{v} / \mathrm{v}$ for 3-day blocks, respectively. This gives a total of 9 days of alcohol administration during which time significant amounts of hepatocellular damage were reported, as demonstrated by marked increases in ALT and development of clinical signs. ${ }^{7}$ The $N r f 2^{-l-}$ mouse thus provides a good model to study severe acute liver injury, as seen in the setting of $\mathrm{AAH}$, where oxidative stress is an important factor. ${ }^{45,46}$ However, the high level of mortality reported necessitates close monitoring of mice. No evidence of liver fibrosis was presented in this model, which potentially limits its utility given most patients with AAH have concomitant fibrosis, although its absence may be explained by the short duration of alcohol administration. However, it is possible that modification and extension of the regimen could potentially induce development of fibrosis. The acute onset of injury in this model presents a challenge because the cohort of mice with severe liver injury are identified by their moribund appearance, and this occurs at varying time points after exposure to the high concentration of alcohol, making the model difficult to use for both logistic and ethical reasons.

Other groups have targeted hepatic lipid homeostasis to exacerbate alcohol-induced liver injury. Lipin-1 is a vital regulator of lipid metabolism, acting as an enzyme in the triglyceride synthesis pathway and a transcriptional coregulatory protein that is highly up-regulated in alcoholic fatty liver disease. $\mathrm{Hu}$ et $\mathrm{al}^{16}$ demonstrated that administering alcohol to mice with deletion of lipin-1 led to the rapid onset of severe liver injury, as indicated by levels of serum ALT and inflammatory cytokines, and progression to alcoholic steatohepatitis. In this study, mice were fed the low-fat LdC diet, with and without ethanol for 4 weeks. WT mice typically developed only mild liver injury, whereas the lipin-1 knockout mice showed increased serum levels of ALT, AST, and free fatty acids, as well as microvesicular and macrovesicular steatosis, suggesting that lipin-1 may exert a protective role by limiting inflammation and promoting efficient lipid storage and metabolism.

Nishiyama et $\mathrm{al}^{15}$ also investigated fat deposition. They used a hepatocyte-specific hypoxia-inducible factor (HIF)$1 \mathrm{a}-$ null mouse to show that HIF-1 has a protective role that reduces accumulation of lipids in the liver after ingestion of an alcohol/LdC liquid diet. They were also able to show that HIF- $1 \alpha$ suppresses sterol response element binding protein$1 \mathrm{c}$ activity and that is at least part of the reason that when HIF- $1 \alpha$ is removed, steatosis increases. However, there are conflicting reports regarding the role of HIFs. Nath et al ${ }^{47}$ also used a HIF-1a-null mouse and found a reduced injury in this knockout mouse, whereas $\mathrm{Ni}$ et $\mathrm{al}^{48}$ achieved similar results using a HIF-1b-null mouse. The reasons for these contrasting results are not clear, although different housing conditions or development of sub-strains within the knockout populations has been suggested. ${ }^{49}$

HIFs have been implicated in the tissue repair response within the liver. They may be involved in regulating the angiogenic effect of hepatic macrophages that induce liver sinusoidal endothelial cell proliferation and migration. ${ }^{50}$ This appears to be a key step in liver repair after an acute injury. Macrophages are likely to be the key to fully 
Intragastric Infusion

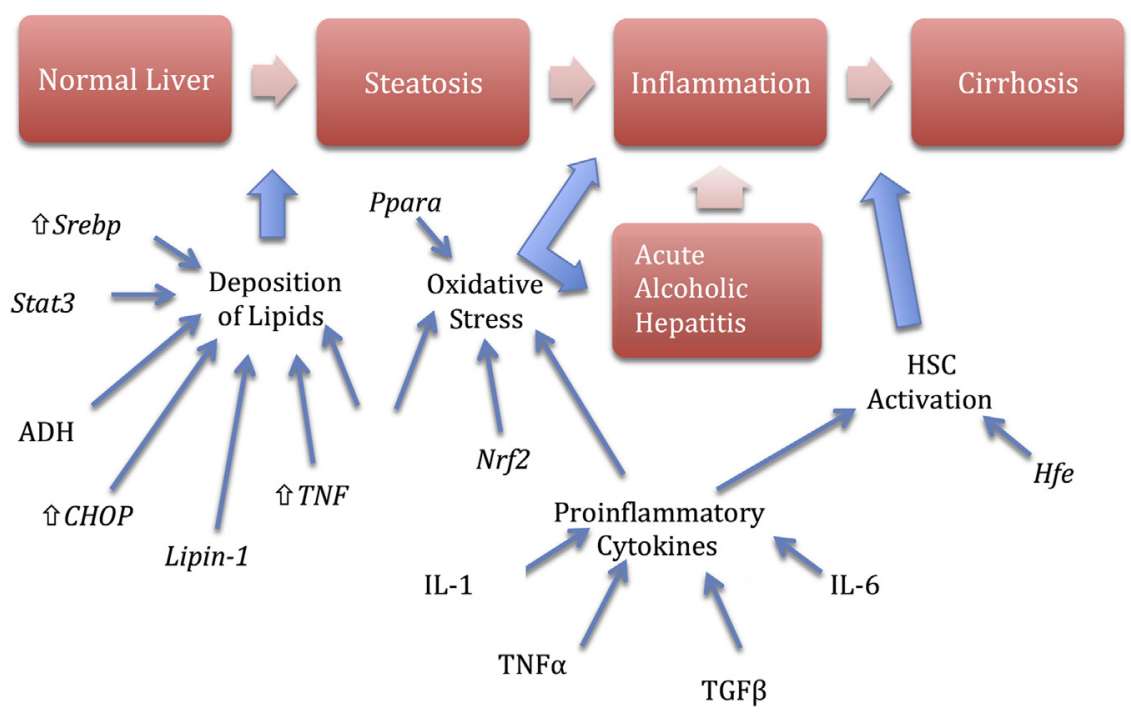

Figure 1 Schematic representation of stages of liver injury induced by different alcohol administration methods. Methods of alcohol administration are indicated by blue bars, and pathological stage appears in the red boxes. The schematic also shows how various transgenic alterations or key genes (black text) can be used to induce a specific stage of liver injury and where certain cytokines are involved in developing a stage of injury. Thus, the identified targets show how it is possible to choose a transgenic mouse depending on what stage of injury is required for investigation. $A D H$, antidiuretic hormone; HSC, hepatic stellate cell; TGF- $\beta$, transforming growth factor- $\beta$; TNF- $\alpha$, tumor necrosis factor- $\alpha$. understand the process of tissue repair in the liver. It has been shown that initially proinflammatory (Ly6C ${ }^{\mathrm{hi}}$ ) macrophages can switch to a Ly6C ${ }^{\text {low }}$ phenotype important in tissue repair ${ }^{51}$ after phagocytosis of apoptotic hepatocytes. Further characterization of the mechanisms driving tissue repair in alcoholic liver injury is needed to identify targets for potential therapies.

Other pathways that have been targeted in the attempt to augment hepatic injury after alcohol exposure include peroxisome proliferator activated receptor- $\alpha$ (Ppar $\alpha)$. Ppar $\alpha$ is a nuclear hormone receptor and transcription factor that regulates hepatic inflammation and lipid metabolism. The role of this receptor is to stimulate fatty acid catabolism under fasting conditions, leading to the hypothesis that free fatty acid production associated with alcohol consumption would normally activate Ppar $\alpha .^{17}$ The Ppara knockout mouse was given an ad libitum LdC liquid diet with $4 \%$ ethanol for up to 6 months, resulting in the development of both an inflammatory cell infiltrate and fibrotic changes that were not seen in alcohol-fed WT mice. This was confirmed by both Picrosirius red and $\alpha$-smooth muscle actin staining, and demonstration of induction of genes involved in fibrosis, including Thbsl, Collal, and Colla2. Ppara transgenic mice with additional genetic alterations provide further options to investigate liver injury. The glutathione $S$-transferase A4-4/Ppar $\alpha$ mouse has been described recently. ${ }^{13}$ Glutathione $S$-transferase A4-4 is an enzyme that protects against natural and environmental toxicants through glutathione conjugation, which protects against harmful aldehydes, including 4-hydroxynonenal. Ronis et $\mathrm{al}^{13}$ have used this double knockout in an ad libitum $\mathrm{LdC} / 5 \%$ ethanol model to show the central role lipid peroxidation plays in mediating progression of alcohol-induced necroinflammatory liver injury, stellate cell activation, matrix remodeling, and fibrosis.

Other alternatives to transgenic knockout mice include transfecting mice with adenoviruses to silence the expression of a specific gene, which reduces, but does not completely turn off, gene expression. The Postic group used this method to show that silencing the carbohydrateresponsive element-binding protein prevents alcoholinduced steatosis in an acute model of injury. ${ }^{52}$ Another strategy is to genetically alter mice to overexpress a certain gene. Butura et $\mathrm{al}^{53}$ used this method to investigate the role of the Cyp $2 e 1$ gene. They inserted approximately 20 extra copies of the gene into mice. They found that overexpression of this gene aggravates the liver injury with increased levels of oxidative stress.

\section{Fibrosis}

The generation of alcohol-induced fibrosis in mouse models is more challenging than steatosis and inflammation and often requires a second injurious element in addition to alcohol ingestion. Bataller and $\mathrm{Gao}^{54}$ have published a comprehensive review on liver fibrosis in alcoholic liver disease. 
There are a variety of nonalcohol models that are used to induce liver fibrosis, with one of the most commonly used being carbon tetrachloride. This involves repeated i.p. injections of carbon tetrachloride over a period of weeks, although there are no studies directly comparing the liver fibrosis induced by carbon tetrachloride with alcohol. Nagy and colleagues ${ }^{37}$ were able to induce liver fibrosis by administering carbon tetrachloride and moderate alcohol intake at a level not usually producing a significant liver injury. This proves the additive effect of the two agents through common pathways. Roychowdury et $\mathrm{al}^{55}$ compared a high ethanol feeding regimen against a moderate ethanol regimen with the addition of carbon tetrachloride. They demonstrated that steatosis, inflammation, and apoptosis were more prevalent in the alcohol-only group compared with the group that also received carbon tetrachloride, which had more prominent fibrosis.

Chiang et $\mathrm{al}^{37}$ exposed mice to $2 \%$ alcohol ad libitum for either 2 days, 2 weeks, or 5 weeks, alongside administration of carbon tetrachloride, which resulted in characteristic hepatic extracellular matrix deposition and a change in sinusoidal architecture. Genetically modified mice deficient in the $\mathrm{HFe}$ (haemochromatosis protein) iron transporter, which causes accumulation of hepatic iron, develop a marked steatohepatitis and fibrosis on administration of a high-fat diet with ethanol. ${ }^{14}$ Versions of this dietary protocol have also been used by other groups combined with other genetic backgrounds. For example, Li et $\mathrm{al}^{17}$ treated Ppara knockout mice with a $4 \%$ ethanol/LdC diet, and after 4 to 6 months, reported fibrosis with a small amount of collagen deposition in perivenular and pericellular regions. In common with other models, a major drawback of this study was the length of time required for fibrosis to develop, as well as the relatively modest amount of fibrosis seen. Notably, other groups have demonstrated that similar or longer regimens are not able to induce significant fibrosis in WT mice, necessitating further study of specific transgenic animals and alternate models of alcohol delivery. ${ }^{54}$

\section{Mouse Variables That Affect Experimental End Points}

There are practical benefits in using a model where mice freely consume alcohol in large quantities. However, as noted above, most mouse strains are not inclined to voluntarily ingest alcohol, and this means that modified liquid diets, gavage, or intragastric infusion is often required. There are marked strain differences in murine attraction to alcohol, and one of the more comprehensive studies compared the consumption of unsweetened alcohol, sweetened alcohol, and sweetened water in 22 in-bred strains of mouse. ${ }^{56}$ The C57B1/6J strain of mice freely consumed the most alcohol, drinking $>10 \mathrm{~g} / \mathrm{kg}$ per day compared with $<2$ $\mathrm{g} / \mathrm{kg}$ per day consumed by DBA/2J mice. Moreover, it has been shown that C57B1/6 mice would consume a diet containing a higher concentration of alcohol than other strains of mice. ${ }^{57}$ Patterns of alcohol consumption over time were also explored, and notably, mice with restricted daily access to alcohol consumed similar quantities to mice that had unlimited 24-hour access, with both groups having similar BALs. ${ }^{58,59}$ It is not clear why the $\mathrm{C} 57 \mathrm{Bl} / 6$ mice are able to consume higher concentrations of alcohol, but there are parallels with consumption in humans, where there is a marked difference in susceptibility to alcohol-induced liver damage across ethnic groups. ${ }^{60}$

Sex is also an important factor in development of alcohol-induced liver injury. Female patients are more susceptible to developing more advanced alcoholic liver damage after both acute and chronic administration, ${ }^{61}$ and similarly female rodents develop more florid liver injury than males after exposure to ethanol. ${ }^{62}$ There are several different theories pertaining to this sex-specific difference, including different alcohol elimination rates, alcohol pharmacokinetics, and estrogen levels. Frezza et $\mathrm{al}^{63}$ were the first to show that in humans, females have decreased levels of gastric antidiuretic hormone, which lessens the first-pass effect on alcohol and increases the bioavailability of ingested alcohol when compared with males. Female mice develop less liver fibrosis when exposed to other types of chronic liver damage, such as carbon tetrachloride injury or hepatitis $\mathrm{C}$ virus infection, suggesting that estrogens may have a protective effect in some disease settings. ${ }^{64,65}$ However, it still needs to be ascertained whether this also applies to alcoholic liver injury; however, it does appear that treatment with estrogen in females lacking ovaries reduces hepatic steatosis. ${ }^{66}$ Also, there are significant sex-specific differences in the response to alcohol at a proteomic level. Wang et $\mathrm{al}^{67}$ found that 90 protein levels were altered by either male or female mice undergoing chronic alcohol feeding, and this included several oxidative stress-related proteins. This is consistent with studies in rats that have found that oxidative stress is a possible reason for increased liver injury in females after ethanol feeding. ${ }^{68}$

Alcohol consumption is different from alcohol metabolism, but female mice seem to have an equal or increased consumption compared with males. Female mice will ingest more alcohol than their male counterparts if given free access to alcohol, although when access is restricted to a defined time period, their intake is similar. ${ }^{69}$ The females also achieve higher BALs after ingesting an equal amount of alcohol as male mice. ${ }^{69}$ This would also seem to mirror the human setting in which women need a lower alcohol intake to achieve equal blood levels to men (National Institute on Alcohol Abuse and Alcoholism, http://pubs.niaaa.nih. gov/publications/womensfact/womensfact.htm, last accessed September 14, 2015). Also, women who drank a moderate amount of alcohol were at higher risk of developing alcoholic liver disease than men who drank a similar amount. $^{70,71}$ All of the above results underline the 
importance of sex in induction of an alcoholic liver injury and reinforce the need to use mice of a single sex in murine models to achieve consistent results.

Age is also an important variable when investigating the effects of alcohol ingestion. Vogt and Richie ${ }^{72}$ showed that glutathione levels take longer to recover after administration of alcohol in mice aged 24 months compared with mice aged 12 months. This would appear to be replicated by other studies. ${ }^{73,74}$ Glutathione is involved in the detoxification of alcohol, and this result would seem to indicate that older mice are less able to metabolize repeated alcohol doses. Further work is required to establish whether this results in increased toxicity and an increased liver injury. However, Ramirez et al ${ }^{75}$ found an increased liver injury in mice $>24$ months when compared with younger mice, although this may be because of decreased rates of autophagy in the older mice. It is not clear whether age reduces a human's ability to metabolize alcohol. Wynne et $\mathrm{al}^{76}$ showed that age did not diminish the activity of alcohol dehydrogenase in the livers of male or female healthy volunteers. However, studies suggest that both age and ethnicity influence the severity of alcoholic liver disease in humans, ${ }^{77}$ and decline in mitochondrial function combined with accumulated oxidative damage in older individuals may render older livers more susceptible to damage from alcohol. ${ }^{78}$ Thus, age is a variable that should be investigated more fully in the context of alcoholic hepatitis.

\section{Comparison of Mouse Models to Human AAH}

Inflammation of the liver, caused by excess alcohol intake, occurs after sustained excessive intake and consists of a combination of signs, symptoms, and histological findings. ${ }^{79}$ Clinically, it causes a rapid onset of jaundice with fever, ascites, and proximal muscle loss that may be accompanied by an enlarged and tender liver. Unfortunately, none of these parameters can be used to demonstrate the relevance of a mouse model to human disease. In patients, serum ALT/AST, bilirubin, and international normalised ratio (INR) are commonly increased and liver histology will reveal the presence of hepatocyte ballooning, which represent amorphous eosinophilic inclusion bodies, called Mallory-Denk bodies, ${ }^{80}$ and a high number of infiltrating neutrophils. Bilirubinostasis is common and associated with susceptibility to infection ${ }^{81}$ and poor survival. ${ }^{82}$ Because of the long history of alcohol excess, steatosis and fibrosis are also commonly seen in human livers.

The level of neutrophil infiltration in the murine liver has been suggested as a measure of how representative a model is of the picture of AAH seen in patients. However, a mouse model that induces a neutrophil infiltration similar to that seen in AAH has been elusive. ${ }^{83}$ Moreover, greater neutrophil infiltration is associated with better survival in humans ${ }^{82}$ and, thus, may not be a sensible therapeutic target. Two older models that have been used in this context are the 3,5-diethoxycarbonyl-1,4-dihydrocollidine and griseofulvin models. These produce ballooning of hepatocytes and accumulation of Mallory bodies but do not involve the administration of alcohol to the mice.

Lamle et $\mathrm{al}^{7}$ were able to induce inflammation within the livers of the $\mathrm{Nrf2} 2^{-I-}$ mice that received $\mathrm{LdC}$ and ethanol diet, which was characterized by histological finding of Kupffer cell and neutrophil infiltration of the liver. The chronic binge-alcohol feeding method also seems to induce a liver injury that is reasonably similar to human $\mathrm{AAH}$, and Bertola et $\mathrm{al}^{31}$ describe increased serum ALT/AST, tumor necrosis factor, and hepatic neutrophil infiltration in this model, albeit without describing the other characteristic histological findings, such as hepatocyte ballooning found in human AAH.

Human alcoholic hepatitis (AH) commonly occurs after repeated, long-term alcohol ingestion with an acute flare-up producing the inflammation. It may be that our mouse models do not reflect this longer-term ingestion and, thus, do not produce the same phenotype of disease. This is supported by the findings of cirrhosis in human biopsy specimens, which is not normally reflected in the mouse models. An elevated bilirubin is not reproduced by any of the mouse models, which may indicate that this feature is linked to the more chronic features of the disease, although how this occurs still needs further clarification.

In the search for murine model/human disease crossover, $\mathrm{Xu}$ et $\mathrm{al}^{84}$ identified murine hepatic Fsp27 and the human homolog Cidec. Both genes are elevated in correlation within a setting of AAH, and Fsp27 is thought to be up-regulated by carbohydrate-responsive element-binding protein and Ppar- $\gamma$. Interestingly, Cidec up-regulation was found to correlate with the degree of hepatic steatosis, severity of disease, and mortality of the $\mathrm{AH}$ patients. $\mathrm{Xu}$ et $\mathrm{al}^{84}$ were able to show that knocking out Fsp27 in the mouse ameliorated the liver injury seen. This suggests that Cidec may be a therapeutic target that could reduce the level of liver injury sustained by patients with $\mathrm{AH}$.

\section{Standardization of End Points for Use in Models of Alcohol-Induced Liver Injury}

The literature includes a range of different readouts and experimental end points that are used to quantify the nature and severity of alcohol-induced liver injury. This diversity can be useful for understanding pathogenesis but is challenging when trying to compare the phenotype of liver damage reported across different models. Moreover, there is value in tailoring the readouts to the focus of a particular study or clinical discipline, whether it is generation of steatosis, inflammation, fibrosis, or cancer. Certain analyses are useful in most studies, such as serum ALT levels, whereas other tests will be specific for the question being asked, such as the amount of fibrosis, as indicated by 
Table 3 Summary of Suggested Tests According to Phenotype of Liver Damage Being Established

\begin{tabular}{|c|c|c|c|c|}
\hline Phenotype of liver injury & Blood analyses & Histological assessment & Flow cytometry & PCR \\
\hline Steatosis & $\begin{array}{l}\text { Serum AST/ALT, } \\
\text { triglycerides, free fatty } \\
\text { acids, and cholesterol }\end{array}$ & $\mathrm{H} \& \mathrm{E}$ and oil red 0 staining & Fatty acid synthase & Chrebp/Srebp, TNFA \\
\hline Acute alcoholic hepatitis & $\begin{array}{l}\text { Serum AST/ALT, markers } \\
\text { of synthetic function } \\
\text { (PT or bilirubin), TNF, } \\
\text { IL-6, and IL-10 }\end{array}$ & $\begin{array}{l}\text { CD45, CD68, CD11b, and } \\
\text { MP0 staining }\end{array}$ & $\begin{array}{l}\text { Identification of } \\
\text { inflammatory cells (ie, } \\
\text { CD3, CD4, CD8, CD19, } \\
\text { and CD45) }\end{array}$ & $\begin{array}{l}\text { Sod1, Stat3, GRP78, } \\
\text { and GRP94 }\end{array}$ \\
\hline Fibrosis & & $\begin{array}{l}\text { Van Gieson or Picrosirius } \\
\text { red staining }\end{array}$ & $\alpha-S M A$ & $\begin{array}{l}\text { Col1, MMP, and } \\
\text { TIMP }\end{array}$ \\
\hline
\end{tabular}

ALT, alanine aminotransferase; AST, aspartate aminotransferase; H\&E, hematoxylin and eosin; MP0, myeloperoxidase; PT, prothrombin time; SMA, smooth muscle actin; TNF, tumor necrosis factor.

$\alpha$-smooth muscle actin. Detail of some of the more common experimental parameters is given below and summarized in Table 3.

\section{Overall Assessment of Murine Behavior and Well-Being}

Murine behavioral patterns are often monitored with a view to animal welfare, although their assessment with standardized scoring systems can provide important information on the effect of alcohol on the mouse. Scoring systems monitor a variety of parameters, including a mouse's coat, activity, breathing, movement, and feces/urine production. Performed reliably, such scoring systems have the potential to provide objective information on the severity of illness in mice, thus providing a censorable end point for experiments, whether they be induction of injury or response to treatment. This bears comparison with clinical scoring systems, such as the Glasgow alcoholic hepatitis score, which increasingly focuses on clinical features of function rather than static measures of liver damage. Given the reported individual variation in level of liver damage after some murine models of ethanol exposure, the added advantage of a clinical assessment is that it ensures mice are more likely to have developed a similar level of liver damage.

\section{Biochemical Assessment of Liver Function}

In the setting of severe liver injury, the most robust assessment of a model should include measurement of parameters of liver synthetic function, such as prothrombin time and serum bilirubin, glucose, and albumin levels. These provide important information on the severity of injury, and can be performed on peripheral blood samples while models are ongoing, thus allowing for the rigorous assessment of potential new therapies. However, because mice have approximately 50 to $60 \mathrm{~mL} / \mathrm{kg}$ of circulating blood (approximately $1.5 \mathrm{~mL}$ for a $25-\mathrm{g}$ mouse) (National Center for the Replacement Raroair. Mouse: decision tree for blood sampling, http://www.nc3rs.org.uk/mousedecision-tree-blood-sampling, last accessed September 14, 2015), there are limitations on the number of blood tests that can ethically and physiologically be performed on live animals.

\section{Assessment of Liver Damage and Hepatocyte Death}

Liver damage, as opposed to function, can be assessed in a variety of ways, ranging from the measurement of serum ALT/AST to scoring of liver histology. Serum ALT/AST are commonly measured in studies and provide a standardized measurement of liver damage. This is generally used to compare the extent of liver damage across studies using different models and different strains of mice, although there is a strain-dependent difference in susceptibility to injury. For example, Mizuhara et al ${ }^{85}$ have shown that ALT levels vary significantly between $\mathrm{C} 57 \mathrm{Bl} / 6$ and $\mathrm{BALB} / \mathrm{c}$ mice after induction of liver injury with concanavalin A. Hematoxylin and eosin staining of liver sections provides valuable information on the extent of tissue necrosis, inflammation, and steatosis, and TUNEL staining can allow quantification of the amount of apoptosis. Histological analysis for the presence of hepatocyte ballooning and the presence of Mallory bodies by ubiquitin staining ${ }^{86}$ is of particular relevance in the setting of $\mathrm{AAH}$, whereas the analyses of superoxide dismutase 1 and malondialdehyde may provide useful insights into the level of oxidative stress during acute liver injury. ${ }^{87}$

\section{Assessment of Liver Steatosis}

Although hematoxylin and eosin staining gives a qualitative indication as to the extent of steatosis, quantitative assessment can be performed using Oil Red O staining of liver sections and digital imaging or morphometric analysis alongside quantification of hepatic triglycerides and lipids. The liver/body weight ratio can also provide an indication of the extent of steatosis, although it can be confounded by concomitant liver necrosis. More detailed analysis of steatosis can also include analysis of key molecules in pathways contributing to its development, such as sterol response element binding proteins, which are involved in cholesterol and fatty acid biosynthesis. ${ }^{18}$

\section{Assessment of Liver Inflammation}

Immunohistochemical staining of liver provides data on the extent and composition of liver-infiltrating inflammatory 
cells, which can be complemented by flow cytometric analysis of resident immune cells from liver cell digests. For example, neutrophil infiltration in models of alcoholic hepatitis has been assessed using both immunochemical staining ${ }^{88}$ and cytometric detection of Ly6G-positive cells in liver digests. ${ }^{89}$ Cell digest analysis can provide detailed quantitative information on the composition of the liver infiltrate and determination of the activation status of any infiltrating cells. This can also be supplemented with analysis of cytokines, such as tumor necrosis factor, IL-6, and IL-10, from serum and liver tissues at message and protein levels to provide useful information on the level of inflammation and the impact of any therapeutic intervention. ${ }^{90}$ For example, in humans, IL-6, IL-8, tumor necrosis factor, and monocyte chemoattractant protein-1 have all been implicated in neutrophil infiltration in patients with alcoholic hepatitis, ${ }^{91,92}$ whereas in mice, IL-4 appears to promote neutrophil survival and hepatitis. ${ }^{93}$

\section{Assessment of Liver Fibrosis}

Standardized assessment of liver fibrosis should include morphometric analysis of fibrotic areas by Picrosirius red or Van Gieson staining, real-time quantitative PCR for Coll transcripts, and biochemical assays of fibrosis, such as hepatic hydroxyproline quantification. ${ }^{94}$ Useful additional insights can be gained by studying staining for activated hepatic stellate cells using $\alpha$-smooth muscle actin and transcription levels of matrix metalloproteinases and their tissue inhibitors.

\section{Additional Mechanistic Studies}

Existing mouse models are useful in replicating human disease but, as discussed above, they have limitations. One interesting area that could be expanded on in the future is the use of genome-wide association studies to identify human pathways/molecules involved in alcoholic liver injury. Current results from these studies have helped identify an allele that has an association with alcoholic liver injury. ${ }^{95}$ Other studies have identified specific genes that have a role in the pathogenesis of alcoholic liver injury, such as osteopontin. ${ }^{96}$ There is potential to expand on this work to identify further genes that put individuals at risk of developing severe alcoholic liver injury. This clinical information could be used to generate new transgenic mice to investigate pathways involved in alcohol metabolism, help future refining of animal models, and discover new treatments for alcoholic liver disease.

Thus, future mechanistic studies may consider useful biomarkers to identify individuals at risk of experiencing alcoholic liver injury. ${ }^{97}$ Manna et al ${ }^{98}$ used metabolomics to show that indole-3-lactic acid and phenyl lactic acid are potential biomarker candidates. However, microarray data have identified that serum insulin-like growth factor binding protein 1 could provide an easily measured biomarker for early detection of alcohol-induced liver injury. ${ }^{99}$ The Szabo group reported that miRNAs may serve as biomarkers that can differentiate between hepatocyte inflammation and injury. They found that different miRNAs can be elevated by alcoholic, drug-induced, or inflammatory liver disease. ${ }^{100}$

\section{Conclusion}

Murine models of alcoholic liver disease are an invaluable tool that can be used to investigate the whole spectrum of alcohol-induced liver damage encountered in the human population. Murine models have several advantages that allow researchers to investigate the full time course and specific mechanisms of the disease in more depth than is possible from human studies. It is clear that before commencing any mouse model work, the human liver injury feature to be replicated must be identified. When this is known, a specific mouse model can be chosen by selecting a transgenic mouse, the alcohol administration method, and the duration/amount of alcohol required to replicate that clinical picture. However, researchers should exert caution and ensure that factors such as sex, age, and strain of mice are carefully considered. This is vital to ensure the mouse liver injury mirrors that seen in patients and, thus, provides a robust means in which to test new pathophysiological mechanisms or therapeutic agents.

\section{References}

1. Rehm J, Samokhvalov AV, Shield KD: Global burden of alcoholic liver diseases. J Hepatol 2013, 59:160-168

2. Saucedo R: Background Paper 6.14. Harmful Use of Alcohol Alcohol Use Disorders and Alcoholic Liver Diseases. World Health Organisation, 2013. Available at http://www.who.int/medicines/areas/priority medicines/BP6_14Alcohol.pdf

3. Hislop WS, Bouchier IA, Allan JG, Brunt PW, Eastwood M, Finlayson ND, James O, Russell RI, Watkinson G: Alcoholic liver disease in Scotland and northeastern England: presenting features in 510 patients. Q J Med 1983, 52:232-243

4. Mathurin P, O'Grady J, Carithers RL, Phillips M, Louvet A, Mendenhall CL, Ramond MJ, Naveau S, Maddrey WC, Morgan TR: Corticosteroids improve short-term survival in patients with severe alcoholic hepatitis: meta-analysis of individual patient data. Gut 2011, 60:255-260

5. Mathurin P, Abdelnour M, Ramond MJ, Carbonell N, Fartoux L, Serfaty L, Valla D, Poupon R, Chaput JC, Naveau S: Early change in bilirubin levels is an important prognostic factor in severe alcoholic hepatitis treated with prednisolone. Hepatology 2003, 38:1363-1369

6. de la M Hall P, Lieber CS, DeCarli LM, French SW, Lindros KO, Jarvelainen H, Bode C, Parlesak A, Bode JC: Models of alcoholic liver disease in rodents: a critical evaluation. Alcohol Clin Exp Res 2001, 25(5 Suppl ISBRA):254S-261S

7. Lamle J, Marhenke S, Borlak J, von Wasielewski R, Eriksson CJ, Geffers R, Manns MP, Yamamoto M, Vogel A: Nuclear factoreythroid 2-related factor 2 prevents alcohol-induced fulminant liver injury. Gastroenterology 2008, 134:1159-1168

8. Fernando H, Bhopale KK, Boor PJ, Ansari GA, Kaphalia BS: Hepatic lipid profiling of deer mice fed ethanol using (1)H and (3)(1)P NMR spectroscopy: a dose-dependent subchronic study. Toxicol Appl Pharmacol 2012, 264:361-369

9. Kaphalia BS, Bhopale KK, Kondraganti S, Wu H, Boor PJ, Ansari GA: Pancreatic injury in hepatic alcohol dehydrogenase- 
deficient deer mice after subchronic exposure to ethanol. Toxicol Appl Pharmacol 2010, 246:154-162

10. Han H, Hu J, Lau MY, Feng M, Petrovic LM, Ji C: Altered methylation and expression of ER-associated degradation factors in long-term alcohol and constitutive ER stress-induced murine hepatic tumors. Front Genet 2013, 4:224

11. Ji C, Mehrian-Shai R, Chan C, Hsu YH, Kaplowitz N: Role of CHOP in hepatic apoptosis in the murine model of intragastric ethanol feeding. Alcohol Clin Exp Res 2005, 29:1496-1503

12. Kono H, Bradford BU, Yin M, Sulik KK, Koop DR, Peters JM, Gonzalez FJ, McDonald T, Dikalova A, Kadiiska MB, Mason RP, Thurman RG: CYP2E1 is not involved in early alcohol-induced liver injury. Am J Physiol 1999, 277(6 Pt 1): G1259-G1267

13. Ronis MJ, Mercer KE, Gannon B, Engi B, Zimniak P, Shearn CT, Orlicky DJ, Albano E, Badger TM, Petersen DR: Increased 4hydroxynonenal protein adducts in male GSTA4-4/PPAR-alpha double knockout mice enhance injury during early stages of alcoholic liver disease. Am J Physiol Gastrointest Liver Physiol 2015, 308: G403-G415

14. Tan TC, Crawford DH, Jaskowski LA, Subramaniam VN, Clouston AD, Crane DI, Bridle KR, Anderson GJ, Fletcher LM: Excess iron modulates endoplasmic reticulum stress-associated pathways in a mouse model of alcohol and high-fat diet-induced liver injury. Lab Invest 2013, 93:1295-1312

15. Nishiyama Y, Goda N, Kanai M, Niwa D, Osanai K, Yamamoto Y, Senoo-Matsuda N, Johnson RS, Miura S, Kabe Y, Suematsu M: HIF-1alpha induction suppresses excessive lipid accumulation in alcoholic fatty liver in mice. J Hepatol 2012, 56:441-447

16. Hu M, Yin H, Mitra MS, Liang X, Ajmo JM, Nadra K, Chrast R, Finck BN, You M: Hepatic-specific lipin-1 deficiency exacerbates experimental alcohol-induced steatohepatitis in mice. Hepatology 2013, 58:1953-1963

17. Li HH, Tyburski JB, Wang YW, Strawn S, Moon BH, Kallakury BV, Gonzalez FJ, Fornace AJ Jr: Modulation of fatty acid and bile acid metabolism by peroxisome proliferator-activated receptor alpha protects against alcoholic liver disease. Alcohol Clin Exp Res 2014, 38 : $1520-1531$

18. Ji C, Chan C, Kaplowitz N: Predominant role of sterol response element binding proteins (SREBP) lipogenic pathways in hepatic steatosis in the murine intragastric ethanol feeding model. J Hepatol 2006, 45:717-724

19. Ki SH, Park O, Zheng M, Morales-Ibanez O, Kolls JK, Bataller R, Gao B: Interleukin-22 treatment ameliorates alcoholic liver injury in a murine model of chronic-binge ethanol feeding: role of signal transducer and activator of transcription 3. Hepatology 2010, 52:1291-1300

20. Ji C, Deng Q, Kaplowitz N: Role of TNF-alpha in ethanol-induced hyperhomocysteinemia and murine alcoholic liver injury. Hepatology $2004,40: 442-451$

21. Sun F, Xie ML, Xue J, Wang HB: Osthol regulates hepatic PPAR alpha-mediated lipogenic gene expression in alcoholic fatty liver murine. Phytomedicine 2010, 17:669-673

22. Tan TC, Crawford DH, Jaskowski LA, Murphy TL, Santrampurwala N, Crane D, Clouston AD, Subramaniam VN, Anderson GJ, Fletcher LM: A corn oil-based diet protects against combined ethanol and ironinduced liver injury in a mouse model of hemochromatosis. Alcohol Clin Exp Res 2013, 37:1619-1631

23. Song K, Coleman RA, Zhu X, Alber C, Ballas ZK, Waldschmidt TJ, Cook RT: Chronic ethanol consumption by mice results in activated splenic T cells. J Leukoc Biol 2002, 72:1109-1116

24. Fan J, Edsen-Moore MR, Turner LE, Cook RT, Legge KL, Waldschmidt TJ, Schlueter AJ: Mechanisms by which chronic ethanol feeding limits the ability of dendritic cells to stimulate T-cell proliferation. Alcohol Clin Exp Res 2011, 35:47-59

25. Zhang H, Meadows GG: Chronic alcohol consumption perturbs the balance between thymus-derived and bone marrow-derived natural killer cells in the spleen. J Leukoc Biol 2008, 83:41-47
26. Roede JR, Stewart BJ, Petersen DR: Decreased expression of peroxiredoxin 6 in a mouse model of ethanol consumption. Free Radic Biol Med 2008, 45:1551-1558

27. Kirpich IA, Feng W, Wang Y, Liu Y, Barker DF, Barve SS, McClain CJ: The type of dietary fat modulates intestinal tight junction integrity, gut permeability, and hepatic toll-like receptor expression in a mouse model of alcoholic liver disease. Alcohol Clin Exp Res 2012, 36:835-846

28. Shearn CT, Smathers RL, Backos DS, Reigan P, Orlicky DJ, Petersen DR: Increased carbonylation of the lipid phosphatase PTEN contributes to Akt2 activation in a murine model of early alcohol-induced steatosis. Free Radic Biol Med 2013, 65: 680-692

29. Wei X, Shi X, Zhong W, Zhao Y, Tang Y, Sun W, Yin X, Bogdanov B, Kim S, McClain C, Zhou Z, Zhang X: Chronic alcohol exposure disturbs lipid homeostasis at the adipose tissue-liver axis in mice: analysis of triacylglycerols using high-resolution mass spectrometry in combination with in vivo metabolite deuterium labeling. PLoS One 2013, 8:e55382

30. Cui Y, Ye Q, Wang H, Li Y, Xia X, Yao W, Qian H: Aloin protects against chronic alcoholic liver injury via attenuating lipid accumulation, oxidative stress and inflammation in mice. Arch Pharm Res 2014, 37:1624-1633

31. Bertola A, Park O, Gao B: Chronic plus binge ethanol feeding synergistically induces neutrophil infiltration and liver injury in mice: a critical role for E-selectin. Hepatology 2013, 58:1814-1823

32. Zhu L, Wang L, Wang X, Luo X, Yang L, Zhang R, Yin H, Xie D, Pan Y, Chen Y: Hepatic deletion of Smad7 in mouse leads to spontaneous liver dysfunction and aggravates alcoholic liver injury. PLoS One 2011, 6:e17415

33. Nanji AA, French SW: Animal models of alcoholic liver disease: focus on the intragastric feeding model. Alcohol Res Health 2003, 27 : 325-330

34. Tsukamoto H, French SW, Benson N, Delgado G, Rao GA, Larkin EC, Largman C: Severe and progressive steatosis and focal necrosis in rat liver induced by continuous intragastric infusion of ethanol and low fat diet. Hepatology 1985, 5:224-232

35. Yan AW, Fouts DE, Brandl J, Starkel P, Torralba M, Schott E, Tsukamoto H, Nelson KE, Brenner DA, Schnabl B: Enteric dysbiosis associated with a mouse model of alcoholic liver disease. Hepatology 2011, 53:96-105

36. Loftus N, Barnes A, Ashton S, Michopoulos F, Theodoridis G, Wilson I, Ji C, Kaplowitz N: Metabonomic investigation of liver profiles of nonpolar metabolites obtained from alcohol-dosed rats and mice using high mass accuracy MSn analysis. J Proteome Res 2011, 10:705-713

37. Chiang DJ, Roychowdhury S, Bush K, McMullen MR, Pisano S, Niese K, Olman MA, Pritchard MT, Nagy LE: Adenosine 2A receptor antagonist prevented and reversed liver fibrosis in a mouse model of ethanol-exacerbated liver fibrosis. PLoS One 2013, 8: e69114

38. Gabele E, Dostert K, Dorn C, Patsenker E, Stickel F, Hellerbrand C: A new model of interactive effects of alcohol and high-fat diet on hepatic fibrosis. Alcohol Clin Exp Res 2011, 35:1361-1367

39. Bykov I, Palmen M, Piirainen L, Lindros KO: Oral chronic ethanol administration to rodents by agar gel diet. Alcohol Alcohol 2004, 39: 499-502

40. Bertola A, Mathews S, Ki SH, Wang H, Gao B: Mouse model of chronic and binge ethanol feeding (the NIAAA model). Nat Protoc 2013, 8:627-637

41. Lazaro R, Wu R, Lee S, Zhu NL, Chen CL, French SW, Xu J, Machida K, Tsukamoto H: Osteopontin deficiency does not prevent but promotes alcoholic neutrophilic hepatitis in mice. Hepatology 2015, 61:129-140

42. Chang B, Xu MJ, Zhou Z, Cai Y, Li M, Wang W, Feng D, Bertola A, Wang H, Kunos G, Gao B: Short- or long-term high fat diet feeding plus acute ethanol binge synergistically induce acute liver injury in 
mice: an important role for CXCL1. Hepatology 2015, 62: $1070-1085$

43. You M, Considine RV, Leone TC, Kelly DP, Crabb DW: Role of adiponectin in the protective action of dietary saturated fat against alcoholic fatty liver in mice. Hepatology 2005, 42: $568-577$

44. Chen YL, Peng HC, Wang XD, Yang SC: Dietary saturated fatty acids reduce hepatic lipid accumulation but induce fibrotic change in alcohol-fed rats. Hepatobiliary Surg Nutr 2015, 4:172-183

45. Cederbaum AI, Lu Y, Wu D: Role of oxidative stress in alcoholinduced liver injury. Arch Toxicol 2009, 83:519-548

46. Gao B, Bataller R: Alcoholic liver disease: pathogenesis and new therapeutic targets. Gastroenterology 2011, 141:1572-1585

47. Nath B, Levin I, Csak T, Petrasek J, Mueller C, Kodys K, Catalano D, Mandrekar P, Szabo G: Hepatocyte-specific hypoxiainducible factor-1alpha is a determinant of lipid accumulation and liver injury in alcohol-induced steatosis in mice. Hepatology 2011, 53:1526-1537

48. Ni HM, Bhakta A, Wang S, Li Z, Manley S, Huang H, Copple B, Ding WX: Role of hypoxia inducing factor-1beta in alcohol-induced autophagy, steatosis and liver injury in mice. PLoS One 2014, 9: e115849

49. Mehal WZ: HIF-1alpha is a major and complex player in alcohol induced liver diseases. J Hepatol 2012, 56:311-312

50. You Q, Holt M, Yin H, Li G, Hu CJ, Ju C: Role of hepatic resident and infiltrating macrophages in liver repair after acute injury. Biochem Pharmacol 2013, 86:836-843

51. Wang M, You Q, Lor K, Chen F, Gao B, Ju C: Chronic alcohol ingestion modulates hepatic macrophage populations and functions in mice. J Leukoc Biol 2014, 96:657-665

52. Marmier S, Dentin R, Daujat-Chavanieu M, Guillou H, BertrandMichel J, Gerbal-Chaloin S, Girard J, Lotersztajn S, Postic C: Novel role for carbohydrate responsive element binding protein in the control of ethanol metabolism and susceptibility to binge drinking. Hepatology 2015, 62:1086-1100

53. Butura A, Nilsson K, Morgan K, Morgan TR, French SW, Johansson I, Schuppe-Koistinen I, Ingelman-Sundberg M: The impact of CYP2E1 on the development of alcoholic liver disease as studied in a transgenic mouse model. J Hepatol 2009, 50:572-583

54. Bataller R, Gao B: Liver fibrosis in alcoholic liver disease. Semin Liver Dis 2015, 35:146-156

55. Roychowdhury S, Chiang DJ, Mandal P, McMullen MR, Liu X, Cohen JI, Pollard J, Feldstein AE, Nagy LE: Inhibition of apoptosis protects mice from ethanol-mediated acceleration of early markers of CCl4-induced fibrosis but not steatosis or inflammation. Alcohol Clin Exp Res 2012, 36:1139-1147

56. Yoneyama N, Crabbe JC, Ford MM, Murillo A, Finn DA: Voluntary ethanol consumption in 22 inbred mouse strains. Alcohol 2008, 42: $149-160$

57. Le AD, Ko J, Chow S, Quan B: Alcohol consumption by C57BL/6, $\mathrm{BALB} / \mathrm{c}$, and DBA/2 mice in a limited access paradigm. Pharmacol Biochem Behav 1994, 47:375-378

58. Matson LM, Grahame NJ: Pharmacologically relevant intake during chronic, free-choice drinking rhythms in selectively bred high alcohol-preferring mice. Addict Biol 2013, 18:921-929

59. Finn DA, Belknap JK, Cronise K, Yoneyama N, Murillo A, Crabbe JC: A procedure to produce high alcohol intake in mice. Psychopharmacology 2005, 178:471-480

60. Shield KD, Gmel G, Kehoe-Chan T, Dawson DA, Grant BF, Rehm J: Mortality and potential years of life lost attributable to alcohol consumption by race and sex in the United States in 2005. PLoS One 2013, 8:e51923

61. Mandayam S, Jamal MM, Morgan TR: Epidemiology of alcoholic liver disease. Semin Liver Dis 2004, 24:217-232

62. Nanji AA, Jokelainen K, Fotouhinia M, Rahemtulla A, Thomas P, Tipoe GL, Su GL, Dannenberg AJ: Increased severity of alcoholic liver injury in female rats: role of oxidative stress, endotoxin, and chemokines. Am J Physiol Gastrointest Liver Physiol 2001, 281: G1348-G1356

63. Frezza M, di Padova C, Pozzato G, Terpin M, Baraona E, Lieber CS: High blood alcohol levels in women: the role of decreased gastric alcohol dehydrogenase activity and first-pass metabolism. N Engl J Med 1990, 322:95-99

64. Zhang Y, Wu L, Wang Y, Zhang M, Li L, Zhu D, Li X, Gu H, Zhang CY, Zen K: Protective role of estrogen-induced miRNA-29 expression in carbon tetrachloride-induced mouse liver injury. J Biol Chem 2012, 287:14851-14862

65. Shimizu I: Impact of oestrogens on the progression of liver disease. Liver Int 2003, 23:63-69

66. Hong J, Holcomb VB, Kushiro K, Nunez NP: Estrogen inhibits the effects of obesity and alcohol on mammary tumors and fatty liver. Int J Oncol 2011, 39:1443-1453

67. Wang Y, Kou Y, Wang X, Cederbaum A, Wang R: Multifactorial comparative proteomic study of cytochrome P450 2E1 function in chronic alcohol administration. PLoS One 2014, 9:e92504

68. Kono H, Wheeler MD, Rusyn I, Lin M, Seabra V, Rivera CA, Bradford BU, Forman DT, Thurman RG: Gender differences in early alcohol-induced liver injury: role of CD14, NF-kappaB, and TNFalpha. Am J Physiol Gastrointest Liver Physiol 2000, 278: G652-G661

69. Middaugh LD, Kelley BM, Bandy AL, McGroarty KK: Ethanol consumption by C57BL/6 mice: influence of gender and procedural variables. Alcohol 1999, 17:175-183

70. Bellentani S, Tiribelli C, Saccoccio G, Sodde M, Fratti N, De Martin C, Cristianini G: Prevalence of chronic liver disease in the general population of northern Italy: the Dionysos Study. Hepatology 1994, 20:1442-1449

71. Becker U, Deis A, Sorensen TI, Gronbaek M, Borch-Johnsen K, Muller CF, Schnohr P, Jensen G: Prediction of risk of liver disease by alcohol intake, sex, and age: a prospective population study. Hepatology 1996, 23:1025-1029

72. Vogt BL, Richie JP Jr: Glutathione depletion and recovery after acute ethanol administration in the aging mouse. Biochem Pharmacol 2007, 73:1613-1621

73. Tung BT, Rodriguez-Bies E, Ballesteros-Simarro M, Motilva V, Navas P, Lopez-Lluch G: Modulation of endogenous antioxidant activity by resveratrol and exercise in mouse liver is age dependent. J Gerontol A Biol Sci Med Sci 2014, 69:398-409

74. Toroser D, Sohal RS: Age-associated perturbations in glutathione synthesis in mouse liver. Biochem J 2007, 405:583-589

75. Ramirez T, Li Y, Feng D, Xu H, Gao B: Aging promotes chronic binge ethanol feeding-induced liver injury by inhibiting Sirtlautophagy. Poster 1112. Poster sessions. Hepatology 2014, 60(Suppl 1): $92 \mathrm{~A}-196 \mathrm{~A}$

76. Wynne HA, Wood P, Herd B, Wright P, Rawlins MD, James OF: The association of age with the activity of alcohol dehydrogenase in human liver. Age Ageing 1992, 21:417-420

77. Levy RE, Catana AM, Durbin-Johnson B, Halsted CH, Medici V: Ethnic differences in presentation and severity of alcoholic liver disease. Alcohol Clin Exp Res 2015, 39:566-574

78. Boelsterli UA, Lim PL: Mitochondrial abnormalities: a link to idiosyncratic drug hepatotoxicity? Toxicol Appl Pharmacol 2007, 220: 92-107

79. Lucey MR, Mathurin P, Morgan TR: Alcoholic hepatitis. N Engl J Med 2009, 360:2758-2769

80. Basra G, Basra S, Parupudi S: Symptoms and signs of acute alcoholic hepatitis. World J Hepatol 2011, 3:118-120

81. Katoonizadeh A, Laleman W, Verslype C, Wilmer A, Maleux G, Roskams T, Nevens F: Early features of acute-on-chronic alcoholic liver failure: a prospective cohort study. Gut 2010, 59:1561-1569

82. Altamirano J, Miquel R, Katoonizadeh A, Abraldes JG, DuarteRojo A, Louvet A, Augustin S, Mookerjee RP, Michelena J, Smyrk TC, Buob D, Leteurtre E, Rincon D, Ruiz P, Garcia-Pagan JC, Guerrero-Marquez C, Jones PD, Barritt ASt, Arroyo V, Bruguera M, 
Banares R, Gines P, Caballeria J, Roskams T, Nevens F, Jalan R, Mathurin P, Shah VH, Bataller R: A histologic scoring system for prognosis of patients with alcoholic hepatitis. Gastroenterology 2014, 146:1231-1239. e1-6

83. Jaeschke H: Neutrophil-mediated tissue injury in alcoholic hepatitis. Alcohol 2002, 27:23-27

84. Xu MJ, Cai Y, Wang H, Altamirano J, Chang B, Bertola A, Odena G, Lu J, Tanaka N, Matsusue K, Matsubara T, Mukhopadhyay P, Kimura S, Pacher P, Gonzalez FJ, Bataller R, Gao B: Fat-specific protein 27/CIDEC promotes development of alcoholic steatohepatitis in mice and humans. Gastroenterology 2015, 149:1030-1041.e6

85. Mizuhara H, Kuno M, Seki N, Yu WG, Yamaoka M, Yamashita M, Ogawa T, Kaneda K, Fujii T, Senoh H, Fujiwara H: Strain difference in the induction of T-cell activation-associated, interferon gammadependent hepatic injury in mice. Hepatology 1998, 27:513-519

86. Vyberg M, Leth P: Ubiquitin: an immunohistochemical marker of Mallory bodies and alcoholic liver disease. APMIS Suppl 1991, 23:46-52

87. Cui Y, Ye Q, Wang H, Li Y, Yao W, Qian H: Hepatoprotective potential of Aloe vera polysaccharides against chronic alcohol-induced hepatotoxicity in mice. J Sci Food Agric 2014, 94:1764-1771

88. Zhong W, Zhao Y, Sun X, Song Z, McClain CJ, Zhou Z: Dietary zinc deficiency exaggerates ethanol-induced liver injury in mice: involvement of intrahepatic and extrahepatic factors. PLoS One 2013, 8:e76522

89. Cui K, Yan G, Xu C, Chen Y, Wang J, Zhou R, Bai L, Lian Z, Wei H, Sun R, Tian Z: Invariant NKT cells promote alcohol-induced steatohepatitis through interleukin-1beta in mice. J Hepatol 2015, 62: $1311-1318$

90. Das SK, Varadhan S, Gupta G, Mukherjee S, Dhanya L, Rao DN, Vasudevan DM: Time-dependent effects of ethanol on blood oxidative stress parameters and cytokines. Indian J Biochem Biophys 2009, 46:116-121

91. Bautista AP: Neutrophilic infiltration in alcoholic hepatitis. Alcohol 2002, 27:17-21
92. Fisher NC, Neil DA, Williams A, Adams DH: Serum concentrations and peripheral secretion of the beta chemokines monocyte chemoattractant protein 1 and macrophage inflammatory protein 1alpha in alcoholic liver disease. Gut 1999, 45:416-420

93. Wang H, Feng D, Park O, Yin S, Gao B: Invariant NKT cell activation induces neutrophil accumulation and hepatitis: opposite regulation by IL-4 and IFN-gamma. Hepatology 2013, 58: $1474-1485$

94. Iredale JP: Models of liver fibrosis: exploring the dynamic nature of inflammation and repair in a solid organ. J Clin Invest 2007, 117: 539-548

95. Tian C, Stokowski RP, Kershenobich D, Ballinger DG, Hinds DA: Variant in PNPLA3 is associated with alcoholic liver disease. Nat Genet 2010, 42:21-23

96. Seth D, Duly A, Kuo PC, McCaughan GW, Haber PS: Osteopontin is an important mediator of alcoholic liver disease via hepatic stellate cell activation. World J Gastroenterol 2014, 20:13088-13104

97. Manna SK, Thompson MD, Gonzalez FJ: Application of mass spectrometry-based metabolomics in identification of early noninvasive biomarkers of alcohol-induced liver disease using mouse model. Adv Exp Med Biol 2015, 815:217-238

98. Manna SK, Patterson AD, Yang Q, Krausz KW, Idle JR, Fornace AJ, Gonzalez FJ: UPLC-MS-based urine metabolomics reveals indole-3lactic acid and phenyllactic acid as conserved biomarkers for alcoholinduced liver disease in the Ppara-null mouse model. J Proteome Res 2011, 10:4120-4133

99. Li HH, Doiron K, Patterson AD, Gonzalez FJ, Fornace AJ Jr: Identification of serum insulin-like growth factor binding protein 1 as diagnostic biomarker for early-stage alcohol-induced liver disease. J Transl Med 2013, 11:266

100. Bala S, Petrasek J, Mundkur S, Catalano D, Levin I, Ward J, Alao H, Kodys K, Szabo G: Circulating microRNAs in exosomes indicate hepatocyte injury and inflammation in alcoholic, druginduced, and inflammatory liver diseases. Hepatology 2012, 56 : 1946-1957 